\title{
Effectiveness, Complications, and Costs of Rheumatoid Arthritis Treatment with Biologics in Alberta: Experience of Indigenous and Non-indigenous Patients
}

\author{
Cheryl Barnabe, Yufei Zheng, Arto Ohinmaa, Louise Crane, Tyler White, Brenda Hemmelgarn, \\ Gilaad G. Kaplan, Liam Martin, and Walter P. Maksymowych
}

ABSTRACT. Objective. To examine clinical effectiveness, treatment complications, and healthcare costs for indigenous and non-indigenous Albertans with rheumatoid arthritis (RA) participating in the Alberta Biologics Pharmacosurveillance program.

Methods. Patients initiating biologic therapy in Alberta (2004-2012) were characterized for disease severity and treatment response. Provincial hospitalization separations, physician claims, outpatient department data, and emergency department data were used to estimate treatment complication event rates and healthcare costs.

Results. Indigenous patients $(\mathrm{n}=90)$ presented with higher disease activity [mean 28-joint count Disease Activity Score (DAS28) 6.11] than non-indigenous patients ( $\mathrm{n}=1400$, mean DAS28 5.19, $\mathrm{p}<0.0001$ ). Improvements in DAS28, function, swollen joint count, CRP, and patient and physician global evaluation scores were comparable to non-indigenous patients, but indigenous patients did not have a significant improvement in erythrocyte sedimentation rate $(-0.31$ per month, $95 \% \mathrm{CI}-0.79$ to $0.16, \mathrm{p}=0.199)$. At the end of study followup, $13 \%(12 / 90)$ of indigenous and $33 \%(455 / 1400)$ of non-indigenous patients were in DAS28 remission $(\mathrm{p}<0.001)$. Indigenous patients had a $40 \%$ increased risk of all-cause hospitalization [adjusted incidence rate ratio (IRR) $1.4,95 \%$ CI $1.1-1.8$, $\mathrm{p}=0.01]$ and a 4-fold increase in serious infection rate (adjusted IRR 4.0, 95\% CI 2.3-7.0, p < 0.001). Non-indigenous patients incurred higher costs for RA-related hospitalizations (difference $\$ 896,95 \%$ CI 520-1273, p < 0.001), and outpatient department visits (difference \$128, 95\% CI 2-255, p = 0.047). Conclusion. We identified disparities in treatment outcomes, safety profiles, and patient-experienced effects of RA for the indigenous population in Alberta. These disparities are critical to address to facilitate and achieve desired RA outcomes from individual and population perspectives. (First Release June 1 2018; J Rheumatol 2018;45; 1344-52; doi:10.3899/jrheum.170779)

Key Indexing Terms:

RHEUMATOID ARTHRITIS OUTCOMES

From the Department of Medicine and Department of Community Health Sciences, Cumming School of Medicine, University of Calgary, Calgary; Institute of Health Economics; Department of Medicine, Faculty of Medicine and Dentistry, and School of Public Health, University of Alberta; Canadian Arthritis Patient Alliance; Siksika Health and Wellness, Siksika Nation, Edmonton, Alberta.

Funding from MSI Foundation Inc. (Grant \#864), Canadian Institutes of Health Research (CIHR) New Investigator in Community-based Primary Health Care, CIHR Foundation Scheme (FDN 143284).

C. Barnabe, MD, MSc, Department of Medicine and Department of Community Health Sciences, Cumming School of Medicine, University of Calgary; Y. Zheng, PhD, Institute of Health Economics, and Department of Medicine, Faculty of Medicine and Dentistry, University of Alberta; A. Ohinmaa, PhD, Institute of Health Economics, and School of Public Health, University of Alberta; L. Crane, MA, Patient Advocate, Canadian Arthritis Patient Alliance; T. White, CEO, Siksika Health and Wellness, Siksika Nation; B. Hemmelgarn, MD, PhD, Department of Medicine and Department of Community Health Sciences, Cumming School of Medicine, University of Calgary; G.G. Kaplan, MD, MPH, Department of Medicine and Department of Community Health Sciences, Cumming School of Medicine, University of Calgary; L. Martin, MB, Department of Medicine, Cumming School of Medicine, University of Calgary; W.P. Maksymowych, $M D$, Department of Medicine, Faculty of Medicine and Dentistry, University of Alberta.

Address correspondence to Dr. C. Barnabe, 3330 Hospital Dr NW, Calgary, Alberta T2N 4A9, Canada.E-mail: ccbarnab@ucalgary.ca Accepted for publication February 12, 2018.

\section{BIOLOGICS ABORIGINAL}

Biologic therapies provide rheumatoid arthritis (RA) patients who have disease refractory to disease-modifying antirheumatic drugs (DMARD) therapeutic options to abrogate disease progression and disability. About one-fourth of patients with RA require biologic therapy ${ }^{1,2}$, and there are several biologic registries worldwide that provide insight into clinical response and outcomes ${ }^{3,4}$. These registries may provide critical information to identify disparity in treatment outcomes between populations of patients, such as on the basis of ethnicity and race; these disparities then indicate which health services interventions are needed to close gaps in care.

The indigenous population in Canada (also referred to as Aboriginal, inclusive of First Nations, Métis, and Inuit) constitutes $4.3 \%$ of the total population ${ }^{5}$. In Alberta, the prevalence of RA in the First Nations population is 3-fold higher than in the non-First Nations population after standardization for age and sex ${ }^{6}$; no estimates are available for Métis and Inuit populations. Contemporary treatment outcomes for indigenous peoples during RA therapy,

Personal non-commercial use only. The Journal of Rheumatology Copyright $\odot$ $)$ 2018. All rights reserved 
including treatment efficacy, safety, or economic considerations, are not described despite evidence of more severe, erosive, and refractory disease ${ }^{7}$, and different underlying risk profiles for adverse events related to comorbid conditions. We have previously demonstrated relatively low rates of use of biologic therapy for Treaty First Nations and Inuit receiving medication cost coverage through the Non-insured Health Benefits Program ${ }^{8}$, but outcomes and adverse events were not studied. One prior study of Manitoba indigenous patients with RA reported a higher number of DMARD exposures and higher use of combination therapy or corticosteroids ${ }^{9}$, but risk estimates for infection and cardiovascular events influenced by steroid exposure were not reported in that study.

The Alberta Biologics Pharmacosurveillance Program (ABioPharm) was established as a prospective population-based cohort of patients with RA to examine the efficacy and safety of biologic treatments. Patients receiving publicly funded biologic therapies in Alberta were characterized for sociodemographic and treatment history at inception to the cohort, and with disease activity, treatment exposure, and adverse effects recorded throughout longitudinal followup. In a unique data-sharing agreement between the universities of Alberta and Calgary, Alberta Health, and the Institute of Health Economics, ABioPharm was linked to provincial administrative healthcare datasets, allowing the application of validated International Classification of Diseases (ICD) codes to identify treatment complications, and to the vital statistics registry to examine mortality rates. The specific objective of our analysis was to examine clinical effectiveness, treatment complications, and healthcare costs for self-identified indigenous and non-indigenous Albertans, including treatment severity at presentation to biologic therapy, treatment persistence, response in disease activity measures and frequency of remission, rates of treatment complications (including all-cause hospitalization, serious infections, malignancies, cardiovascular events), mortality, and healthcare use costs.

\section{MATERIALS AND METHODS}

Sources of data. ABioPharm was initiated with funding provided by Alberta Health to record the efficacy, safety, and cost efficiency of new biologic therapies for $\mathrm{RA}^{10}$. Patients with disease refractory to standard DMARD therapy and initiating biologic therapy were enrolled into ABioPharm between April 2004 and November 2012, regardless of insurer. The 2 data components of ABioPharm are a clinical database and provincial administrative healthcare databases.

Clinical database. Assessments of disease activity, function, and quality of life occurred at the start of a new biologic agent, 3 months after initiation of that drug, and then annually if no treatment switches were required. Patients completed a standardized set of questionnaires including demographic questions, the Self-Administered Comorbidity Questionnaire ${ }^{11}$, and physical function measured by the Health Assessment Questionnaire (HAQ) ${ }^{12}$. Tender, swollen, and damaged joint counts were collected, as were inflammatory markers [erythrocyte sedimentation rate (ESR) and C-reactive protein (CRP)] and medication exposure. The data were collected by nurse specialists and research coordinators located in Edmonton and Calgary, where all rheumatologists in the province were situated, and entered into a Web-based database maintained by Epicore in Edmonton.

Provincial administrative healthcare databases. Alberta Health maintains administrative databases for the Alberta Health Care Insurance Plan, which can be linked to identify medical diagnoses ascertained through outpatient visits to primary care physicians and specialists in the Practitioner Payments and Ambulatory Care database, inpatient admissions and procedures in the Inpatient Discharge Abstract database, and the Vital Statistics Registry to examine mortality. The dates used in analysis were fiscal years 2004/2005 to $2011 / 2012$.

Study population and ethics. Parental ethnicity was self-reported within the ABioPharm clinical database. An individual was classified to be "indigenous" for those with either parent listed as First Nations, Inuit, or Métis, and "non-indigenous" for all other participants who had indicated their ethnicity (white, South Asian, Asian, Hispanic, Black, or other). Patients provided informed consent in accordance with ethical standards described in the Declaration of Helsinki, and with approval from the University of Calgary Health Research Ethics Board (Ethics ID E-20425) and the University of Alberta Research Ethics Board (Ethics Study ID Pro00000914). An amendment to consider population-specific analysis was granted in 2012 by the University of Calgary Health Research Ethics Board.

Outcomes. Disease severity at presentation to biologic therapy was considered, including disease duration at biologic initiation, assessment of disease severity [mean tender and swollen joint counts, levels of inflammatory markers (ESR in $\mathrm{mm} / \mathrm{h}, \mathrm{CRP}$ in $\mathrm{mg} / \mathrm{l}$ ), patient's and physician's global assessments (10-cm Visual Analog Scale), HAQ score ${ }^{12}$, and DAS28 score $^{13}$. Treatment persistence was estimated as the median duration of each biologic agent. The response in disease activity measures were modeled adjusting for baseline differences between population groups in disease activity, disease duration, and sociodemographic factors. The proportion of patients in DAS28 remission at the final assessment was calculated. The administrative databases were used to estimate treatment complication event rates and healthcare use costs. Each hospitalization was identified from the Discharge Abstract Database to provide the estimates for all-cause hospitalization. We applied validated algorithms based on ICD 9th revision, Clinical Modification and ICD 10th revision, Canada codes for infections ${ }^{14,15}$ and cardiovascular events ${ }^{16,17,18}$ (Appendix 1) to determine all events for those complications. Serious infection was defined as any of the following: (1) primary reason for hospitalization; (2) primary reason for ambulatory care visit in conjunction with intravenous administration of antibiotics; or (3) cause of death in the Vital Statistics Registry. Diagnostic codes used to define malignancy were provided by Dr. S. Bernatsky (Appendix 1), and only the first event with a diagnosis code was included. Linkage of administrative health datasets to the Vital Statistics Registry was used to determine mortality. Healthcare use costs for outpatient physician visits, hospitalizations, emergency room visits, and outpatient department visits for each patient were estimated.

Statistical analysis. Student $\mathrm{t}$ test or chi-squared tests were used to compare baseline descriptive characteristics between indigenous and non-indigenous participants. To account for baseline differences in disease activity and repeated measure identification, we used longitudinal mixed modeling to first adjust the baseline disease activity measures, and then estimate the rate of change in the disease activity measure over the time course of exposure to the first biologic agent. Covariates were baseline DAS28, age, sex, disease duration at index date, current smoking status, and baseline HAQ score. The proportion of patients in remission and low disease activity at last assessment was contrasted between population groups by the chi-squared test. For each category of treatment complication, event rates per 100 person-years (PY) were calculated for indigenous and non-indigenous patients. An incidence rate ratio (IRR) was calculated to compare all-cause hospitalization, serious infections, cancer (all types; and separately for lung, breast, colorectal, and hematologic malignancies), cardiovascular events (composite of myocardial infarction, cerebrovascular accident, congestive heart failure, and each type separately), and mortality between indigenous and non-indigenous partici-

Personal non-commercial use only. The Journal of Rheumatology Copyright $\subset$ 2018. All rights reserved. 
pants. IRR was adjusted using Poisson regression for age at biologic start, sex, income, education, urban versus rural residence, number of comorbidities, current or past smoking, number of previous DMARD, seropositive status, baseline DAS28 and HAQ scores, history of joint replacement, number of rheumatology visits between cohort entry and index date, and overweight or obese status. Missing variable imputation was used. For calculation of healthcare use costs, physician services were obtained from the Alberta Health billing records, which included the diagnostic code for each service, actual service provided, fee paid for the service, and the specialty of the doctor. Multiple claims occurring on the same calendar day were assumed to be attributed to the same medical service. Estimates of total cost (outpatient physician, hospitalization, emergency room, outpatient clinic), as well as costs attributable specifically to RA using a previously developed algorithm ${ }^{19,20}$ were constructed. Median annual total healthcare costs (standardized to 2008 Canadian dollars using the Canadian Consumer Price Index) were estimated for indigenous and non-indigenous patients from these visits using a 2-part model with propensity score adjustment to estimate the difference between population groups. Our modeling accounts for the skewness and zero mass of health costs introduced by patients who had not incurred any costs in that category ${ }^{21,22}$. In the first part, a Probit model was applied to estimate the probability that the patient had health costs, which addresses those patients who had no costs in that category and the mass zero number of dependent variables. In the second part, we estimated the difference in health costs between indigenous and non-indigenous patients who had costs incurred using a generalized linear model with gamma family, which recognizes the skewness of health costs. Because the patient characteristics were imbalanced, we applied propensity score subclassification methods to reduce the potential bias.

Analyses were conducted using SAS version 9.3 (clinical database), and Stata version 13 (StataCorp; administrative database).

\section{RESULTS}

Inception characteristics. The ABioPharm cohort accrued a total of 1608 persons exposed to biologic therapies, of which 90 identified as indigenous ethnicity, and 1400 identified as non-indigenous identity (Table 1). There was a total of 7671
PY of followup in the non-indigenous group, and $474 \mathrm{PY}$ of followup in the indigenous group. Indigenous patients were on average 5 years younger at index date, more frequently current smokers but not more frequently seropositive for rheumatoid factor or anticyclic citrullinated peptide antibodies. There were no differences in the proportion of patients with heart disease $(6 \%)$, hypertension $(28 \%)$, lung disease $(7 \%)$, diabetes $(7 \%)$, ulcer or stomach disease $(9 \%)$, liver disease $(2 \%)$, osteoarthritis $(43 \%)$, or cancer $(4 \%)$ between indigenous and non-indigenous groups. Higher rates of kidney disease ( $5 \%$ vs $1 \%, \mathrm{p}=0.03)$, anemia ( $23 \%$ vs $11 \%, \mathrm{p}=0.003)$, depression ( $35 \%$ vs $20 \%, \mathrm{p}=0.0035)$, and back pain $(51 \%$ vs $39 \%, \mathrm{p}=0.04)$ were reported by the indigenous participants. As summarized in Table 1, most disease activity measures were significantly higher in the indigenous patients at baseline, who were initiating a biologic with on average 5 more tender joints and 3 more swollen joints (28-joint count). Both physicians and patients scored the global arthritis activity level as being more severe in indigenous patients.

Treatment persistence. During the observation period, participants were exposed to a mean of 1.6 and a median of 1 biologic agent, with a range of 1-7 agents for non-indigenous patients and 1-5 agents for indigenous patients. The mean duration for taking biologics was numerically longer in the indigenous participants at 2.5 years (SD 2.1) for nonsmokers and 2.7 years (2.7) for smokers than non-indigenous participants at 2.4 years (2.1) for nonsmokers and 2.3 years (2.2) for smokers; however, these differences were not statistically significant.

Table 1. Baseline sociodemographic characteristics and disease activity of ABioPharm patients, comparing self-identified indigenous to non-indigenous participants. Values are $\mathrm{n}(\%)$ or mean $\pm \mathrm{SD}$ unless otherwise specified.

\begin{tabular}{|c|c|c|c|}
\hline Characteristics & Indigenous, $\mathrm{n}=90$ & Non-indigenous, $n=1400$ & $\mathrm{p}^{*}$ \\
\hline Female & $68(75.6)$ & $1032(73.7)$ & NS \\
\hline Age at index date, yrs & $50.4 \pm 12.2$ & $55.0 \pm 14.0$ & 0.0003 \\
\hline No. DMARD exposures at index date & $3.4 \pm 1.4$ & $3.2 \pm 0.0$ & NS \\
\hline $\mathrm{BMI}, \mathrm{kg} / \mathrm{m}^{2}$ & $27.4 \pm 5.5$ & $26.6 \pm 5.9$ & NS \\
\hline Education, yrs & $11.4 \pm 2.3$ & $12.2 \pm 4.0$ & 0.0005 \\
\hline Anti-CCP-positive & $15 / 21(71.4)$ & $143 / 221(64.7)$ & NS \\
\hline DAS28-ESR & $6.11 \pm 1.42$ & $5.19 \pm 1.65$ & $<0.0001$ \\
\hline $\mathrm{TJC} 28$ & $15.3 \pm 9.3$ & $10.3 \pm 9.5$ & $<0.0001$ \\
\hline SJC28 & $8.7 \pm 6.4$ & $6.1 \pm 6.2$ & $<0.0001$ \\
\hline $\mathrm{ESR}, \mathrm{mm} / \mathrm{h}$ & $33.6 \pm 24.5$ & $30.2 \pm 23.8$ & NS \\
\hline $\mathrm{CRP}, \mathrm{mg} / \mathrm{l}$ & $25.9 \pm 31.8$ & $19.4 \pm 29.4$ & 0.002 \\
\hline
\end{tabular}

* P value reported for significantly different values between groups only. ABioPharm: Alberta Biologics Pharmacosurveillance program; NS: not significant; DMARD: disease-modifying antirheumatic drug; BMI: body mass index; RF: rheumatoid factor; anti-CCP: anticyclic citrullinated peptide antibodies; DAS28-ESR: 28-joint count Disease Activity Score using erythrocyte sedimentation rate; TJC28: 28-joint tender joint count; SJC28: 28-joint swollen joint count; CRP: C-reactive protein; PtGA: patient's global assessment; PGA: physician's global assessment; HAQ: Health Assessment Questionnaire. 
Response in disease activity measures and achievement of remission. Table 2 presents the rates of improvement in disease activity measures and differences in rates of change between indigenous and non-indigenous participants after adjustment. For all measures except ESR, both indigenous and non-indigenous patients demonstrated improvement, and the DAS28, swollen joint count, CRP, patient and physician global evaluation, and HAQ scores improved at similar rates in both population groups. The rate of improvement in tender joint counts in indigenous patients compared to non-indigenous patients was slower (difference in slope $0.09,95 \%$ CI $0.03-0.15, p=0.004)$. ESR did not significantly improve for indigenous patients over time (slope $-0.31,95 \% \mathrm{CI}-0.79$ to $0.16, \mathrm{p}=0.199$ ) although it did for non-indigenous patients (slope $-0.83,95 \% \mathrm{CI}-0.99$ to $-0.67, \mathrm{p}<0.001$ ). At last assessment, $13 \%(12 / 90)$ of indigenous patients were in DAS28 remission compared to $33 \%(455 / 1400)$ of non-indigenous patients $(\mathrm{p}<0.001)$.

Rates of treatment complications. The crude all-cause hospitalization rate was not different between indigenous and non-indigenous patients, but after adjusting for covariates, indigenous patients had a $40 \%$ increased risk of admission (adjusted IRR 1.4, 95\% CI 1.1-1.8, $\mathrm{p}=0.01$; Table 3). The adjusted incidence rate of serious infections in indigenous patients was estimated to be 4 times that occurring in non-indigenous patients (adjusted IRR 4.0, 95\% CI 2.3-7.0, $\mathrm{p}<0.001$ ). This was primarily driven by increased infections of the renal tract, bone and skin, and soft tissue in indigenous patients. Rates of herpes zoster infections were not significantly different between population groups. No episodes of active tuberculosis were identified. The composite of all malignancies also revealed an adjusted 2.6-fold increased risk in indigenous patients (95\% CI 1.1-5.7, p = 0.02). The composite of all cardiovascular events (myocardial infarction, congestive heart failure, and cerebrovascular accident) was similar between population groups after adjustments for covariates despite a numerically different estimate between the populations (20 events per $100 \mathrm{PY}$ in non-indigenous vs
4 events per $100 \mathrm{PY}$ in indigenous). A mortality rate ratio could not be calculated because there were no deaths in the indigenous population group. There were 52 deaths in non-indigenous patients for a mortality rate of 0.67 per $100 \mathrm{PY}$.

Healthcare use costs. Mean, median, and adjusted differences of costs for hospitalizations, emergency department visits, outpatient clinic departments, and physician visits between indigenous and non-indigenous patients are shown in Table 4. Estimates for costs directly associated with RA and those associated with non-RA visits are also listed. Non-indigenous patients incurred higher costs for RA-specific hospitalizations (difference $\$ 896,95 \%$ CI 520-1273, p < 0.001), as well as for both total (difference $\$ 289,95 \%$ CI $12-566, p=0.041$ ) and RA-related (difference $\$ 128,95 \%$ CI $2-255, p=0.047$ ) outpatient clinic visits compared to non-indigenous patients. Numerically, mean and median costs for emergency department use were higher for the indigenous patients, but this was not statistically different in the adjusted models. Costs for physician visits were similar between population groups.

\section{DISCUSSION}

Our study reports on multiple aspects of clinical outcomes in patients with RA requiring biologic therapies, specifically comparing outcomes between indigenous and non-indigenous patients. It is important to note first that indigenous patients represent $6 \%$ of our cohort, which is in keeping with Statistics Canada estimates of the indigenous population in Alberta $^{5}$, but at odds with our estimates of RA affecting at least 3 times as many First Nations people compared to non-First Nations in our province ${ }^{6}$. This at the very least suggests that comparatively fewer indigenous patients with RA are able to access biologic therapies, because indigenous patients are consistently found to have more frequent ${ }^{23}$ and severe disease ${ }^{7}$, and our results are generalizable only to those patients who have successfully navigated the healthcare system to acquire care for RA refractory to first-line therapies.

Table 2. Adjusted* baseline disease activity measures and rate of change (per 12 months) during treatment with first biologic agent.

\begin{tabular}{|c|c|c|c|c|c|c|}
\hline \multirow[t]{3}{*}{ Variables } & \multicolumn{4}{|c|}{ Adjusted Rate of Change } & \multicolumn{2}{|c|}{ Difference in Rate of Change } \\
\hline & \multicolumn{2}{|c|}{ Indigenous Patients } & \multicolumn{2}{|c|}{ Non-indigenous Patients } & \multirow[b]{2}{*}{ Mean $(95 \% \mathrm{CI})$} & \multirow[b]{2}{*}{$\mathrm{p}$} \\
\hline & Slope $(95 \%$ CI $)$ & $\mathrm{p}$ & Slope $(95 \%$ CI) & $\mathrm{p}$ & & \\
\hline TJC28 & $-0.14(-0.19$ to -0.08$)$ & $<0.001$ & $-0.23(-0.26$ to -0.20$)$ & $<0.001$ & $0.09(0.03-0.15)$ & 0.004 \\
\hline SJC28 & $-0.21(-0.25$ to -0.18$)$ & $<0.001$ & $-0.24(-0.27$ to -0.21$)$ & $<0.001$ & $0.03(-0.02$ to 0.08$)$ & 0.315 \\
\hline ESR & $-0.31(-0.79$ to 0.16$)$ & 0.199 & $-0.83(-0.99$ to -0.67$)$ & $<0.001$ & $0.52(0.01-1.02)$ & 0.045 \\
\hline PGA & $-0.27(-0.34$ to -0.20$)$ & 0.001 & $-0.34(-0.36$ to -0.32$)$ & $<0.001$ & $0.07(-0.01$ to 0.14$)$ & 0.074 \\
\hline HAQ & $-0.04(-0.06$ to -0.03$)$ & 0.001 & $-0.05(-0.06$ to -0.05$)$ & $<0.001$ & $0.01(-0.01$ to 0.03$)$ & 0.238 \\
\hline
\end{tabular}

* Adjusted for baseline DAS28, age, sex, disease duration at index date, current smoking status, and baseline HAQ score. DAS28: 28-joint count Disease Activity Score; TJC28: 28-joint tender joint count; SJC28: 28-joint swollen joint count; ESR: erythrocyte sedimentation rate; CRP: C-reactive protein; PtGA: patient's global assessment; PGA: physician's global assessment; HAQ: Health Assessment Questionnaire.

Personal non-commercial use only. The Journal of Rheumatology Copyright $\subset$ 2018. All rights reserved. 
Table 3. Treatment complications during biologic therapy, comparing self-identified indigenous to non-indigenous patients.

\begin{tabular}{|c|c|c|c|c|}
\hline Outcome & $\begin{array}{l}\text { Indigenous } \\
\text { Event Rate }\end{array}$ & $\begin{array}{l}\text { Non-indigenous } \\
\text { Event Rate }\end{array}$ & $\begin{array}{l}\text { Adjusted IRR } \\
\quad(95 \% \mathrm{CI})\end{array}$ & $\mathrm{p}$ \\
\hline All-cause hospitalization & 17.7 & 17.7 & $1.4(1.1-1.8)$ & 0.01 \\
\hline Serious infection & 3.4 & 1.4 & $4.0(2.3-7.0)$ & $<0.001$ \\
\hline \multicolumn{5}{|l|}{ Cancer } \\
\hline Any malignancy & 1.5 & 1.3 & $2.6(1.1-5.7)$ & 0.02 \\
\hline Lung & 0.2 & 0.1 & $1.9(0.2$ to 17.5$)$ & 0.57 \\
\hline Breast & 0.0 & 0.1 & $\mathrm{NC}$ & \\
\hline Colorectal & 0.0 & 0.1 & $\mathrm{NC}$ & \\
\hline Lymphoproliferative & 0.2 & 0.1 & $2.3(0.3-20.5)$ & 0.45 \\
\hline \multicolumn{5}{|l|}{ Cardiovascular } \\
\hline Composite event rate & 4.2 & 20.0 & $0.8(0.4-1.6)$ & 0.45 \\
\hline Myocardial infarction & 0.8 & 0.7 & $3.5(1.2-10.2)$ & 0.08 \\
\hline Congestive heart failure & 1.5 & 10.0 & $0.6(0.3-1.2)$ & 0.13 \\
\hline Cerebrovascular accident & 1.9 & 9.4 & $0.6(0.3-1.3)$ & 0.17 \\
\hline Mortality & 0.0 & 0.7 & $\mathrm{NC}$ & \\
\hline
\end{tabular}

IRR: incidence rate ratio; NC: not calculable.

Table 4. Mean, median, and adjusted healthcare use costs for RA patients receiving biologic therapy, comparing indigenous and non-indigenous populations*.

\begin{tabular}{|c|c|c|c|c|c|c|}
\hline \multirow{2}{*}{ Costs } & \multicolumn{2}{|c|}{ Crude Mean (SD) } & \multicolumn{2}{|c|}{ Crude Median (IQR) } & \multirow{2}{*}{$\begin{array}{l}\text { Difference, Estimate } \\
(95 \% \mathrm{CI})\end{array}$} & \multirow[t]{2}{*}{$\mathrm{p}$} \\
\hline & Indigenous & Non-indigenous & Indigenous & Non-indigenous & & \\
\hline Hospital, total & $1833(6839)$ & $2552(14,010)$ & $0(0)$ & $0(0)$ & -1203 (-2966 to 561$)$ & 0.181 \\
\hline RA-specific & 225 (1114) & $951(6554)$ & $0(0)$ & $0(0)$ & $-896(-1273$ to -520$)$ & $<0.001$ \\
\hline Non-RA conditions & $1608(6748)$ & $1602(11,073)$ & $0(0)$ & $0(0)$ & 58 (-1936 to 2052$)$ & 0.96 \\
\hline Emergency department, total & $530(982)$ & $204(548)$ & $111(575)$ & $0(138)$ & $110(-28$ to 249$)$ & 0.12 \\
\hline RA-specific & $159(461)$ & $63(230)$ & $0(78)$ & $0(0)$ & $31(-35$ to 97$)$ & 0.354 \\
\hline Non-RA conditions & $370(656)$ & $141(422)$ & $107(459)$ & $0(103)$ & $85(-16$ to 185$)$ & 0.099 \\
\hline Outpatient clinic, total & $746(1138)$ & $961(2065)$ & $439(819)$ & $443(1036)$ & $-289(-566$ to -12$)$ & 0.041 \\
\hline RA-specific & $302(912)$ & $359(845)$ & $56(199)$ & $79(320)$ & $-128(-255$ to -2$)$ & 0.047 \\
\hline Non-RA conditions & $444(464)$ & $602(1746)$ & $299(598)$ & $280(714)$ & $-179(-381$ to 22$)$ & 0.082 \\
\hline Physician, total & 1474 (1269) & $1547(2079)$ & $1036(1453)$ & $970(1346)$ & $-229(-625$ to 168$)$ & 0.259 \\
\hline RA-specific & $725(582)$ & $693(822)$ & $508(832)$ & $432(626)$ & $-70(-235$ to 94$)$ & 0.402 \\
\hline Non-RA conditions & $748(975)$ & 854 (1587) & $399(718)$ & $441(822)$ & $-141(-424$ to 141$)$ & 0.326 \\
\hline
\end{tabular}

*All amounts are in Canadian dollars. RA: rheumatoid arthritis; IQR: interquartile range.

There were important differences in baseline characteristics between the indigenous and non-indigenous patients in our study. Although younger at presentation for biologic therapy, there was a higher frequency of comorbidities in indigenous patients that could affect assessment, treatment, and prognosis. For example, smoking was associated with worse disease outcomes and reduced odds of achieving disease remission ${ }^{24,25,26}$. All major disease activity measures were significantly worse in the indigenous population, indicating a higher burden of inflammation experienced. Biology-based differences that drive worse disease severity and phenotype ${ }^{27}$ are suggested in cohorts of First Nations with RA in Manitoba, including a high prevalence of HLA shared epitope alleles ${ }^{28}$ and other genetic risks ${ }^{29}$, a high prevalence of RA autoantibodies ${ }^{30}$, and increased exposure to environmental risks such as smoking and periodontal disease. These factors have not been specifically studied in Alberta indigenous populations but are potential explanations for our observations. Pertinent to this discussion is the effect of intergenerational trauma and chronic stress in indigenous populations in Canada ${ }^{31}$, and the linking of exposure to trauma to the risk for RA in the Nurses' Health Study ${ }^{32}$ supports further investigation of how trauma history may affect disease severity. Alternatively, contributing factors discovered in our prior work on systemic barriers to care are also plausibly influencing disease severity at presentation, including increased use of primary care as compared to specialty care services ${ }^{6}$, avoiding presenting for care in inadequate systems ${ }^{33}$, and different access criteria for biologics for Treaty First Nations persons prior to March $2014^{8}$. Delays in diagnosis and initiating DMARD therapy at disease onset could also explain a different disease course because the 
"window of opportunity" was missed; however, these data are not available in our registry. Unfortunately, the location of residence of participants was not collected, and thus we cannot assess for potential geographic barriers to care. Indeed, all rheumatologists in the province are located in the major metropolitan cities (Calgary and Edmonton), thus requiring patients to travel for consultation; however, this may be tempered by the growing proportion of indigenous persons residing in urban centers ${ }^{5}$.

Although improvement occurred at a similar rate for most disease activity measures compared to non-indigenous patients, with the exception of inflammatory markers and tender joint count, there were ultimately fewer patients from the indigenous population who achieved remission. Although not confirmed in our study directly with an assessment of radiographic progression, persistent disease activity is associated with damage and eventually disability ${ }^{34}$. This prioritizes the need to address RA outcomes more proactively. A healthcare equity lens is useful to examine root causes of, and consider potential interventions to resolve, disparities in risk for RA and access to appropriate care, considered here as an all-encompassing view of health service provision and quality of care. It is not yet known whether RA can be prevented, but it is compelling to consider public health initiatives that would mitigate RA risk factors. For example, enhancing access to appropriate dental care to reduce periodontal disease, and interventions to address smoking, are potential solutions. It is thus critical to recall the treatment goals and standards that are indicated in RA, namely early treatment initiation and treat-to-target ${ }^{35}$, and to identify different strategies and approaches that resonate with indigenous patients and are complementary to biologic therapy that might be needed to achieve optimal disease control. For example, implicit bias in the health system can fuel health disparities and contribute to poor outcomes ${ }^{36}$; possible solutions are providing culturally appropriate care systems and integration of both indigenous and non-indigenous healing systems, as suggested by the Truth and Reconciliation Commission ${ }^{37}$. An emerging literature specific to indigenous populations through patient-centered care plans and those that involve shared decision-making strategies may be useful to help begin to address health equity gaps $^{38,39}$ and requires further study in the context of RA.

The safety analysis has identified differences in the rates of adverse events during biologic therapy. Indigenous patients had a significantly higher rate of all-cause hospitalization, and serious infections occurred at a rate 4 times that of non-indigenous patients, after adjustments for important confounders. There was also an indication for increased malignancy development, although not found to be directly related to biologic therapy. This addresses the heightened need to collaborate with primary care, and rapidly respond to initial signs of infection or malignancy, allowing intervention at early stages and with heightened screening.
Physician costs were not different between indigenous and non-indigenous patients. Non-indigenous patients incurred higher costs for the use of outpatient care departments, and this indicates the need to ensure that all patients have equitable access to allied health services regardless of ethnicity. Although there was not a statistically significant difference in emergency department visits between population groups, the data trend toward higher mean and median costs in the indigenous population indicates that they may be accessing the system because of crisis situations, or lack of primary care/specialty care providers. This warrants further evaluation.

Our results may not be generalizable to all indigenous populations. Even in our participants, demonstrable gaps were present. A participant's indigenous identity was assumed based on parental ethnicity but may not be how the person self-identifies. The imbalanced sample sizes could affect analysis and the power to detect true differences, and we included as many covariates as possible in our models to adjust for unbalanced prognostic factors. Still, residual bias could remain, and we could not include covariates of potential interest that were not collected, such as measures of cultural resiliency that would impart better health outcomes. We present results on a sample of nearly 1500 patients engaged in care processes for accessing biologic agents in our province, but this may be an underrepresentation of all treated patients with RA. An acknowledged limitation is that co-therapy with DMARD and steroids was not included in our models because of missing exposure window specificity related to the annual followup schedule and the difficulty of attributing exposure to events. Patient-reported outcomes have been collected and are described in detail in a separate publication ${ }^{40}$.

This population-based pharmacosurveillance cohort has identified disparities in treatment outcomes, safety profiles, and patient-experienced effects of RA for the indigenous population in Alberta, despite the use of advanced treatment strategies. It is critical to address these disparities to facilitate and achieve desired RA outcomes from the individual and population perspectives. Coupling research evidence with policy initiatives provides the best opportunity to close the gaps in current inequities in RA outcomes.

\section{ACKNOWLEDGMENT}

The authors thank Dr. Elizabeth Erasmus, past Medical Director, Elbow River Healing Lodge, Aboriginal Health Program, Alberta Health Services; Bonnie Healy, Chief Operating Office, Alberta First Nations Information Governance Centre; and Dr. Sasha Bernatsky, Professor, McGill University.

\section{REFERENCES}

1. Zhang J, Xie F, Delzell E, Chen L, Kilgore ML, Yun H, et al. Trends in the use of biologic agents among rheumatoid arthritis patients enrolled in the US Medicare program. Arthritis Care Res 2013;65:1743-51

2. Widdifield J, Bernatsky S, Paterson JM, Tu K, Ng R, Thorne JC, et al. Accuracy of Canadian health administrative databases in

Personal non-commercial use only. The Journal of Rheumatology Copyright @ 2018 . All rights reserved. 
identifying patients with rheumatoid arthritis: a validation study using the medical records of rheumatologists. Arthritis Care Res 2013;65:1582-91.

3. Elkayam O, Pavelka K. Biologic registries in rheumatology: lessons learned and expectations for the future. Autoimmun Rev 2012;12:329-36.

4. Curtis JR, Jain A, Askling J, Bridges SL Jr., Carmona L, Dixon W, et al. A comparison of patient characteristics and outcomes in selected European and U.S. rheumatoid arthritis registries. Semin Arthritis Rheum 2010;40:2-14.

5. Statistics Canada. 2011 census profile. [Internet. Accessed April 5, 2018.] Available from: www12.statcan.gc.ca/nhs-enm/2011/ dp-pd/prof/index.cfm?Lang=E

6. Barnabe C, Jones CA, Bernatsky S, Peschken CA, Voaklander D, Homik J, et al. Inflammatory arthritis prevalence and health services use in the First Nations and non-First Nations populations of Alberta, Canada. Arthritis Care Res 2017;69:467-74.

7. Hurd K, Barnabe C. Systematic review of rheumatic disease phenotypes and outcomes in the Indigenous populations of Canada, the USA, Australia and New Zealand. Rheumatol Int 2017; 37:503-21.

8. Barnabe C, Healy B, Portolesi A, Kaplan GG, Hemmelgarn B, Weaselhead C. Claims for disease-modifying therapy by Alberta non-insured health benefits clients. BMC Health Serv Res 2016;16:430.

9. Peschken CA, Hitchon CA, Robinson DB, Smolik I, Barnabe CR, Prematilake S, et al. Rheumatoid arthritis in a North American native population: longitudinal followup and comparison with a white population. J Rheumatol 2010;37:1589-95.

10. Barr SG, Martin L, Chung C, Maksymowych WP. Mandatory pharmacosurveillance - a Canadian model for access to therapy and research. Clin Exp Rheumatol Suppl 2004;22 Suppl 35:S39-43.

11. Sangha O, Stucki G, Liang MH, Fossel AH, Katz JN. The Self-Administered Comorbidity Questionnaire: a new method to assess comorbidity for clinical and health services research. Arthritis Rheum 2003;49:156-63.

12. Bruce B, Fries JF. The Health Assessment Questionnaire (HAQ). Clin Exp Rheumatol Suppl 2005;5 Suppl 39:S14-8

13. Prevoo ML, van 't Hof MA, Kuper HH, van Leeuwen MA, van de Putte LB, van Riel PL. Modified disease activity scores that include twenty-eight-joint counts. Development and validation in a prospective longitudinal study of patients with rheumatoid arthritis. Arthritis Rheum 1995;38:44-8.

14. Widdifield J, Bernatsky S, Paterson JM, Gunraj N, Thorne JC, Pope $\mathrm{J}$, et al. Serious infections in a population-based cohort of 86,039 seniors with rheumatoid arthritis. Arthritis Care Res 2013;65:353-61.

15. Barber C, Lacaille D, Fortin PR. Systematic review of validation studies of the use of administrative data to identify serious infections. Arthritis Care Res 2013;65:1343-57.

16. Metcalfe A, Neudam A, Forde S, Liu M, Drosler S, Quan H, et al. Case definitions for acute myocardial infarction in administrative databases and their impact on in-hospital mortality rates. Health Serv Res 2013;48:290-318.

17. McCormick N, Lacaille D, Bhole V, Avina-Zubieta JA. Validity of myocardial infarction diagnoses in administrative databases: a systematic review. PLoS One 2014;9:e92286.

18. McCormick N, Lacaille D, Bhole V, Avina-Zubieta JA. Validity of heart failure diagnoses in administrative databases: a systematic review and meta-analysis. PLoS One 2014;9:e104519.

19. Ohinmaa AE, Thanh NX, Barnabe C, Martin L, Russell AS, Barr SG, et al. Canadian estimates of healthcare utilization costs for rheumatoid arthritis patients with and without biologics therapies. Arthritis Care Res 2014;66:1319-27.

20. Barnabe C, Thanh NX, Ohinmaa A, Homik J, Barr SG, Martin L, et al. Healthcare service utilisation costs are reduced when rheumatoid arthritis patients achieve sustained remission. Ann Rheum Dis 2013;72:1664-8.

21. Mullahy J. Much ado about two: reconsidering retransformation and the two-part model in health econometrics. J Health Econ 1998; 17:247-81.

22. Manning WG, Basu A, Mullahy J. Generalized modeling approaches to risk adjustment of skewed outcomes data. J Health Econ 2005;24:465-88.

23. McDougall C, Hurd K, Barnabe C. Systematic review of rheumatic disease epidemiology in the Indigenous populations of Canada, the United States, Australia, and New Zealand. Semin Arthritis Rheum 2017;46:675-86.

24. Hyrich KL, Watson KD, Silman AJ, Symmons DP; British Society for Rheumatology Biologics Register. Predictors of response to anti-TNF-alpha therapy among patients with rheumatoid arthritis: results from the British Society for Rheumatology Biologics Register. Rheumatology 2006;45:1558-65.

25. Abhishek A, Butt S, Gadsby K, Zhang W, Deighton CM. Anti-TNF-alpha agents are less effective for the treatment of rheumatoid arthritis in current smokers. J Clin Rheumatol 2010;16:15-8.

26. Mattey DL, Brownfield A, Dawes PT. Relationship between pack-year history of smoking and response to tumor necrosis factor antagonists in patients with rheumatoid arthritis. J Rheumatol 2009;36:1180-7.

27. England BR, Thiele GM, Mikuls TR. Anticitrullinated protein antibodies: origin and role in the pathogenesis of rheumatoid arthritis. Curr Opin Rheumatol 2017;29:57-64.

28. El-Gabalawy HS, Robinson DB, Daha NA, Oen KG, Smolik I, Elias $\mathrm{B}$, et al. Non-HLA genes modulate the risk of rheumatoid arthritis associated with HLA-DRB1 in a susceptible North American Native population. Genes Immun 2011;12:568-74.

29. Hitchon CA, Sun Y, Robinson DB, Peschken CA, Bernstein CN, Siminovitch KA, et al. Vitamin D receptor polymorphism rs2228570 (Fok1) is associated with rheumatoid arthritis in North American natives. J Rheumatol 2012;39:1792-7.

30. Hitchon CA, Chandad F, Ferucci ED, Willemze A, Ioan-Facsinay A, van der Woude D, et al. Antibodies to porphyromonas gingivalis are associated with anticitrullinated protein antibodies in patients with rheumatoid arthritis and their relatives. J Rheumatol 2010; 37:1105-12.

31. Bombay A, Matheson K, Anisman H. The impact of stressors on second generation Indian Residential School survivors. Transcult Psychiatry 2011;48:367-91.

32. Lee YC, Agnew-Blais J, Malspeis S, Keyes K, Costenbader K, Kubzansky LD, et al. Post-traumatic stress disorder and risk for incident rheumatoid arthritis. Arthritis Care Res 2016;68:292-8.

33. Thurston WE, Coupal S, Jones CA, Crowshoe LF, Marshall DA, Homik J, et al. Discordant indigenous and provider frames explain challenges in improving access to arthritis care: a qualitative study using constructivist grounded theory. Int J Equity Health 2014;13:46.

34. Navarro-Compan V, Gherghe AM, Smolen JS, Aletaha D, Landewe $\mathrm{R}$, van der Heijde D. Relationship between disease activity indices and their individual components and radiographic progression in RA: a systematic literature review. Rheumatology 2014;54:994-1007.

35. Bykerk VP, Akhavan P, Hazlewood GS, Schieir O, Dooley A, Haraoui B, et al; Canadian Rheumatology Association. Canadian Rheumatology Association recommendations for pharmacological management of rheumatoid arthritis with traditional and biologic disease-modifying antirheumatic drugs. J Rheumatol 2012; 39:1559-82.

36. Allan B, Smylie J. First Peoples, second class treatment: The role of racism in the health and well-being of Indigenous peoples in Canada. Toronto: Wellesley Institute; 2015. 
37. Truth and Reconciliation Commission of Canada. Honouring the Truth, Reconciling for the Future. Summary of the Final Report of the Truth and Reconciliation Commission of Canada. Winnipeg: Truth and Reconciliation Commission of Canada; 2015.

38. Jull J, Crispo J, Welch V, MacDonald H, Brascoupe S, Boyer Y, et al. Interventions for indigenous peoples making health decisions: a systematic review. Pimatisiwin 2014;11:539-54.

39. Jull J, Giles A, Minwaashin Lodge, The Aboriginal Women's Support Centre, Boyer Y, Stacey D. Cultural adaptation of a shared decision making tool with Aboriginal women: a qualitative study. BMC Med Inform Decis Mak 2015;15:1.

40. Barnabe C, Crane L, White T, Hemmelgarn B, Kaplan GG, Martin $\mathrm{L}$, et al. Patient-reported outcomes, resource use, and social participation of patients with rheumatoid arthritis treated with biologics in Alberta: experience of indigenous and non-indigenous patients. J Rheumatol 2018 Feb 15 (E-pub ahead of print). 
APPENDIX 1. ICD-9-CM and ICD-10-CA codes applied to define safety outcomes.

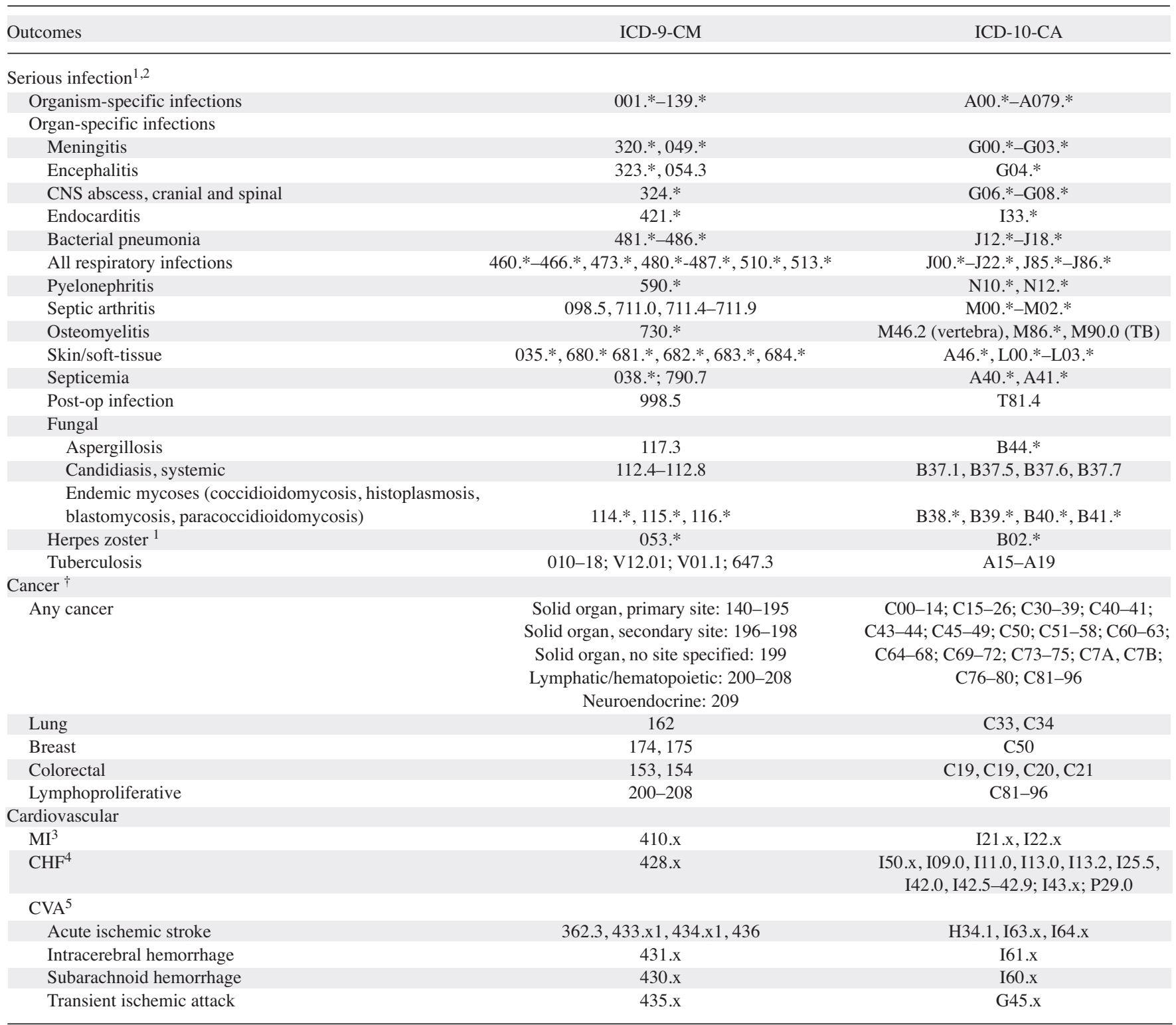

$\dagger$ Provided by S. Bernatsky. ICD-9-CM: International Classification of Diseases 9th revision, Clinical Modification; ICD-10-CA: ICD 10th revision, Canada; CNS: central nervous system; MI: myocardial infarction; CHF: congestive heart failure; CVA: cerebrovascular accident.

1. Widdifield J, Bernatsky S, Paterson JM, Gunraj N, Thorne JC, Pope J, et al. Serious infections in a population-based cohort of 86,039 seniors with rheumatoid arthritis. Arthritis Care Res 2013;65:353-61.

2. Barber C, Lacaille D, Fortin PR. Systematic review of validation studies of the use of administrative data to identify serious infections. Arthritis Care Res 2013;65:1343-57.

3. Metcalfe A, Neudam A, Forde S, Liu M, Drosler S, Quan H, et al. Case definitions for acute myocardial infarction in administrative databases and their impact on in-hospital mortality rates. Health Serv Res 2013;48(1):290-318.

4. McCormick N, Lacaille D, Bhole V, Avina-Zubieta JA. Validity of heart failure diagnoses in administrative databases: a systematic review and meta-analysis. PLoS One 2014;9:e104519.

5. Kokotailo RA, Hill MD. Coding of stroke and stroke risk factors using International Classification of Diseases, revisions 9 and 10. Stroke 2005; 36:1776-81. 